\title{
Analisis Vegetasi Hijauan Pakan Ternak di Area Integrasi dan Non Integrasi Sapi dan Sawit
}

\section{Analysis of Forage for Livestock in Integrated and Non-integrated Cow and Palm Plantation}

\author{
T. Rostini, S. Djaya, dan R. Adawiyah \\ Jurusan Peternakan, Fakultas Pertanian Universitas Islam Kalimantan \\ Jln. Adyaksa no 2 Kayu Tangi Banjarmasin \\ Corresponding email: tintin_rostini@yahoo.com
}

\begin{abstract}
Analysis of forage vegetation of fodder in an integrated and non integrated area of palm oil plantation has been conducted. The purpose of this study aimed to determine the forage vegetation under an integrated palm oil plant that is not integrated with livestock.. This study used purposive sampling observation method and analyzed by $\mathrm{T}$ or T-Test. The results showed that there were ten types of plants in the area of integrated and non-integrated of palm oil plantation. Paspalum conjugatum had the highest relative frequency, the highest density and the Important Value Index (INP) compared to other forages both in the integration and nonintegration areas. The results showed that the forage vegetation of fodder in the integration of oil palm showed higher yields. It was concluded that the integration of oil palm cattle could increase animal feed forage production.
\end{abstract}

Key words: vegetation analysis, relative frequency, important value index, relative density

\begin{abstract}
ABSTRAK
Analisis vegetasi hijauan pakan ternak di area terintegrasi dan non integrasi sapi sawit telah dilaksanakan. Tujuan penelitian ini bertujuan untuk mengetahui vegetasi hijauan di bawah tanaman kelapa sawit yang terintegrasi dan non integrasi dengan ternak Penelitian ini menggunakan metode pengamatan purposive sampling dan dianalisis dengan uji $\mathrm{T}$ atau t-Test. Hasil penelitian menunjukan bahwa terdapat sepuluh jenis tanaman di area integrasi dan non integrasi sapi sawit. Paspalum conjugatum memiliki frekuensi relatif, kerapatan relatif dan Indeks Nilai Penting (INP) tertinggi dibanding hijauan pakan lainnya baik di area integrasi maupun non integrasi Hasil penelitian menunjukkan bahwa vegetasi hijauan pakan ternak diarea integrasi sapi sawit menunjukkan hasil yang lebih tinggi. Disimpulkan bahwa integrasi sapi sawit dapat meningkat produksi hijauan pakan ternak.
\end{abstract}

Kata kunci: analisis vegetasi, frekuensi relatif, indeks nilai penting, kerapatan relatif.

\section{PENDAHULUAN}

Indonesia memiliki tantangan yang cukup serius dalam masalah ketersediaan dan kecukupan pakan seiring dengan semakin meningkatnya perubahan fungsi lahan. Menurut Rohaeni dan Hamdan (2004). Pengembangan program integrasi sapi sawit mempunyai peluang pengembangan yang sangat prospektif ditinjau dari aspek permintaan atas sapi (daging) nasional, ketersediaan pakan sapi melalui sinergi dengan kebun sawit dan hasil sampingan proses pengolahan hasil kebun, serta pemanfaatan kotoran sapi secara maksimal (untuk pembuatan biogas dan pupuk alami). Integrasi produksi ternak dengan perkebunan kelapa sawit dapat menjadi cikal bakal pengembangan agribisnis berbasis ruminan-perkebunan. Berkaitannya dengan pengembangan peternakan. Keuntungan dari pemanfaatan hasil perkebunan kelapa sawit pada usaha peternakan sapi adalah :a) secara teknis bahan pakan inimudah didapat dan produksinaya berkesinambungan: b) secara ekonomi membantu peningkatan pendapatan perkebunan: c) membantu pengawasan lingkungan serta mengurangi pencemaran: d) menambah penyedian bahan pakan (Aritonang, 1986).

Salah satu yang telah menjalankan program integrasi sapi dan kelapa sawityaitu PT. Buana Karya Bhakti. Program (SISKA), dikembangkan pada lahan seluas 3.175 hektar dengan populasi sapi saat ini berjumlah 500 ekor. Di perkebunan sawit banyak tanaman yang tumbuh dibawahnya yang dapat dimanfaatkan sebagai pakan ternak. Namun penelitian dan identifikasi tanaman di lahan perkebunan sawit yang menjadi gulma tersebut masih jarang dilakukan. 
Berdasarkan uraian diatas, perlu adanya penelitian tentang hijauan pakan ternak dibawah tanaman sawit yang diintegrasikan dengan sapi potong dan yang tidak diintegrasikan di perkebunan PT. Buana Karya BhaktiKalimantan Selatan (Kalsel) untuk lebih jauh mengetahui tentang identifikasi hijauan pada area integrasi sapi dan kelapa sawit maupun area non integrasi sapi sawit. Tujuan penelitian ini adalah untuk mengetahui vegetasi hijauan dibawah tanaman kelapa sawit yang terintegrasi dengan sapi dan yang non integrasi dengan sapi pada perkebunan sawit.

\section{MATERI DAN METODE}

Bahan yang digunakan dalam penelitian ini adalah tanaman pakan di area integrasi sapi kelapa sawit dan yang non integrasi dengan ternak sapi, yang terdapat di perkebunan PT. Buana Karya Bhakti - Kalimantan Selatan.

Data dihimpun dengan metode garis petak dari area perkebunan sawit yang diintegrasikan dengan sapi potong dan dari area perkebunan yang tidak diintegrasikan. Setiap petak contoh berbentuk segiempat ukuran $1 \mathrm{~m} \mathrm{x}$ $1 \mathrm{~m}$ petak contoh disusun secara purposive sampling, dengan 5x ulangan, sampel yang diambil dari setiap petak dibuat dengan ukuran 1x1 meter dibawah tanaman kelapa sawit yang terintegrasi dan yang non integrasi. Masingmasing lokasi pengambilan sampel adalah sepuluh blok untuk area integrasi dan 10 blok untuk area non integrasi, sehingga total petak yang dibuat adalah 50 petak penelitian.

Variabel yang diamati adalah jenis tanaman yang ada di area integrasi sawit sapi dan area non integrasi, frekuensi relatif, kerapatan relatif, dan nilai indeks penting.

Rumus yang digunakan:

$$
\begin{array}{ll}
\begin{array}{l}
\text { Frekuensi } \\
\text { Relatif }
\end{array} & =\frac{\text { frekuensi adanya satu spesies }}{\text { frekuensi selruh spesies }} \times 100 \% \\
\begin{array}{c}
\text { Kerapatan } \\
\text { Relatif }
\end{array} & =\frac{\text { jumlah populasi satu spesies }}{\text { jumlah selruh spesies }} \times 100 \%
\end{array}
$$

Indeks Nilai Penting $=\mathrm{FR}+\mathrm{KR}$
Data yang diperoleh ditabulasi selanjutnya untuk mengetahui perbedaan antara lahan yang terintegrasi sapi dan yang non integrasi sapi dilakukan uji t-test (Gaspersz, 1994).

\section{HASIL DAN PEMBAHASAN}

\section{Jenis Vegetasi Tanaman yang Ada di Area Integrasi dan Non integrasi Sapi Sawit}

Jenis vegetasi tanaman yang ada di area yang terintegrasi dan non integrasi sapi sawit perkebunan PT. Buana Karya Bhakti Kalimantan Selatan terdapat lima jenis rumput di area integrasi sapi sawit, yaitu rumput Paspalum conjugatum, Cyrtococcum patens, Axonopus compressus, Cyrtococcum acrescens dan Ageratum conyzoides. Hasil penelitian lebih banyak jenis tanamannya dibandingkan dengan hasil penelitian Adriadi et al. (2012) yang menjelaskan bahwa ada tiga jenis tanaman yang paling dominan di perkebunan kelapa sawit baik di area yang non integrasi atau terintegrasi yaitu rumput Paspalum conjugatum (47\%) mendominasi di perkebunan kelapa sawit integrasi pada kepadatan ternak tinggi maupun pada area non integrasi. Onusimus et al. (2009) menyatakan bahwa Paspalum conjugatum merupakan jenis rumput yang masuk dalam lima jenis rumput yang mendominasi di padang gembalaan sawit dengan presentase pertumbuhan $18,28 \%$.

Berdasarkan Tabel 1, Paspalum conjugatum memiliki jumlah batang yang banyak (27\%) dari total batang pada area integrasi dan 39,8\% pada area non integrasi $\mathrm{Hal}$ ini diduga karena tanaman ini mudah tumbuhnya, penyebaran utama dengan biji dan akan stolon serta memiliki sifat mudah melekat pada bendabenda yang melintas disekitarnya. Senada dengan pendapat Uinutub (2010), tanaman Paspalum conjugatum merupakan jenis rumput yang pertumbuhannya menyebar dengan cepat dan mudah melekat pada tanaman sekitarnya. Kebanyakan tumbuh sebagai gulma yang mengganggu tanaman pertanian terutama tanaman kelapa sawit (Harzinah, 2014). 
Tabel 1. Jenis tanaman yang terdapat di area integrasi dan tidak terintegrasi sapi sawit

\begin{tabular}{clcc}
\hline \multirow{2}{*}{ No } & \multirow{2}{*}{ Jenis rumput } & \multicolumn{2}{c}{ Jumlah (batang) } \\
\cline { 3 - 4 } & Melothria affinis & Integrasi & Non Integrasi \\
\hline 1 & Paspalum conjugatum & 3580 & 263 \\
3 & Mikania micrantha & 224 & 4092 \\
4 & Asystasia intrusa & 448 & 429 \\
5 & Axonopus compressus & 2130 & 300 \\
6 & Davallia denticulate & 223 & 675 \\
7 & Cyrtococcus macrescens & 2030 & 14 \\
8 & Cyrtococcum patens & 3470 & 528 \\
9 & Ageratum conyzoides & 819 & 3523 \\
10 & Nephrolepis bisserrata & 30 & 141 \\
\hline \multicolumn{2}{c}{ Jumlah } & 13117 & 231 \\
\hline
\end{tabular}

\section{Frekuensi relatif}

Frekuensi relatif berdasarkan uji $\mathrm{T}$ tes tanaman Paspalum conjugatum memiliki frekuensi relatif tertinggi yaitu sebesar $25,80 \%$ di area terintegrasi dan $40,33 \%$ di area non integrasi. Frekuensi relatif terendah di area integrasi pada tanaman Nephrolepis bisserrata $(1,40 \%)$. Nephrolepis bisserrata ini saat dilakukan penelitian penyebaranya tidak merata di setiap plot dan ditemukan dalam jumlah yang sedikit sehingga memiliki frekuensi relatif yang terendah di area terintegrasi. Begitupun juga dengan Davallia denticullata $(0,67 \%)$ di area non integrasi merupakan frekuensi relatif terendah karena di area non terintegrasi Davallia denticullata merupakan jenis gulma yang sangat jarang ditemukan. Hasil frekuensi relatif selanjutnya disajikan pada Tabel 2.

Taufan et al.(2015), menyatakan bahwa Paspalum conjugatum memiliki frekuensi relative yang paling tinggi mencapai $45,54 \%$ dibandingkan dengan tanaman gulma lainnya di bawah perkebunan kelapa sawit non integrasi. Hasil penelitian Taufan et al.(2015) sesuai dengan hasil penelitian di PT. Buana Karya Bhakti - Kalsel dimana Paspalum conjugatum memiliki frekuensi relatif tertinggi mencapai $25,80 \%$ di area terintegrasi dan 40,33\% di area non integrasi sapi-sawit. Adriadi et al. (2012) menyatakan bahwa berdasarkan hasil penelitiannya Paspalum conjugatum memiliki penyebaran yang luas dan hampir ditemukan di setiap plot penelitiannya dengan frekuensi relatif tertinggi dibandingkan dengan gulma lain yaitu 9,66\%, diikuti Asystasia intrusa (8,82\%), Axonopus compressus $(6,72 \%)$ dan Ageratum conyzoides $(4,46 \%)$

Analisis frekuensi relatif yang tersaji pada Tabel 2, berdasarkan uji $\mathrm{T}$ atau t-Test menunjukkan tidak berbeda nyata, kecuali pada jenis rumput Cyrtococcum patens. Hal ini diduga terjadi karena Cyrtococcum patens adalah

Tabel 2. Rata-rata frekuensi relatif vegetasi hijauan di area non integrasi dan terintegrasi sapi sawit

\begin{tabular}{llcc}
\hline \multirow{2}{*}{ No } & \multicolumn{2}{c}{ Jenis rumput } & \multicolumn{2}{c}{ Frekuensi relatif $(\%)$} \\
\cline { 3 - 4 } & & Integrasi & Non Integrasi \\
\hline 1 & Melothria affinis & 1,47 & 2,50 \\
2 & Paspalum conjugatum & 25,80 & 40,33 \\
3 & Mikania micrantha & 3,63 & 10,33 \\
4 & Asystasia intrusa & 10,72 & 7,33 \\
5 & Davallia denticullata & 4,23 & 0,67 \\
6 & Cyrtococcum patens & $15,43^{\mathrm{a}}$ & $13,54^{\mathrm{b}}$ \\
7 & Cyrtococcum acrescens & 3,17 & 0,50 \\
8 & Ageratum conyzoides & 9,80 & 1,00 \\
9 & Axonopus ncompressus & 12,33 & 5,17 \\
10 & Nephrolepis bisserrata & 1,40 & 6,17 \\
\hline
\end{tabular}

Keterangan : Huruf yang berbeda mengikuti angka pada baris yang sama menunjukkan berbeda nyata $(\mathrm{P}<0,05 \%)$ 
jenis rumput yang paling disukai ternak. Penyebarannya hampir tidak ditemukan di area integrasi kecuali hanya pada dua blok saja dengan jumlah yang sedikit. Pada area non integrasi yang sama sekali belum terjamah oleh sapi jumlahnya berlimpah terutama pada area dengan umur tanaman kelapa sawit yang masih muda dimana matahari masih dapat leluasa menembus rumput tersebut. Artinya selain ternak, pencahayaan merupakan faktor lain yang mempengaruhi pertumbuhan rumput Cyrtococcum patens, semakin meningkat umur tanaman kelapa sawit, produksi hijauan yang tumbuh di bawahnya akan menurun. Semakin tinggi umur tanaman kelapa sawit penetrasi cahaya yang menerobos daun kelapa sawit semakin rendah sehingga berpengaruh terhadap produksi tanaman yang tumbuh di bawah tanaman kelapa sawit (Wong and Chin, 1998).

\section{Kerapatan Relatif}

Kerapatan relatif tertinggi pada tanaman Paspalum conjugatum dibandingkan dengan rumput lainnya dengan presentase 33,00\% di area terintegrasi dan $40,77 \%$ di area non integrasi. Kerapatan relatif terendah adalah Nephrolepis bisserrata $(0,53 \%)$ di area terintegrasi dan Davallia denticullata $(0,17 \%)$ di area non integrasi. Data lebih lengkap mengenai kerapatan relatif vegetasi hijauan di area yang non integrasi dan terintegrasi sapi-sawit disajikan pada Tabel 3 .

Berdasarkan Tabel 3 menunjukkan baik pada area yang terintegrasi maupun area yang non integrasi, Paspalum conjugatum memiliki kerapatan tertinggi yaitu, 33,00\% di area terintegrasi dan $46,77 \%$ di area non integrasi Hal ini sesuai dengan pernyataan Adriadi et al. (2012) bahwa Paspalum conjugatum memiliki kerapatan tertinggi mencapai $26,16 \%$ dibanding dengan tanaman lainnya.

Hasil Uji $\mathrm{T}$ kerapatan relatif 1 tidak berbeda nyata pada vegetasi hijauan pakan ternak di area non integrasi dan terintegrasi sapi sawit. Hasil berbeda nyata hanya ditunjukkan oleh Ageratum conyzoides. Berdasarkan hasil penelitian di lapangan bahwa Ageratum conyzoides merupakan jenis rumput yang banyak ditemukan hampir di setiap plot penelitian meskipun kemunculannya di setiap plot tidak selalu dalam jumlah yang tinggi. Ageratum conyzoides merupakan jenis rumput yang jarang dimakan oleh sapi jika masih ada rumput lain yang lebih disukai. Menurut McIlroy (1976) dalam Prawirodiputra (2011) penggembalaan ternak di padang rumput dalam jumlah yang cukup tidak akan merusak komposisi vegetasi yang palatabel, sedangkan penggembalaan berlebih maupun penggembalaan ringan dapat menyebabkan komposisi vegetasi berubah menjadi didominasi oleh gulma yang tidak disukai ternak.

Selain itu, kemungkinan jumlah Ageratum conyzoides yang lebih tinggi di area terintegrasi dibandingkan dengan area non integrasi adalah karena kondisi tanah yang lebih subur karena adanya pengaruh kotoran sapi yang menjadi kompos. Ternak ruminansia besar seperti sapi menghasilkan kotoran padat dan cair (urin) yang dapat digunakan sebagai sumber amelioran tanah. Potensi kotoran ternak sebagai sumber karbon (C), nitrogen $(\mathrm{N})$, fosfor $(\mathrm{P})$

Tabel 3. Rata-rata kerapatan relatif vegetasi hijauan di area non integrasi dan terintegrasi sapi-sawit

\begin{tabular}{llcc}
\hline \multirow{2}{*}{ No } & \multirow{2}{*}{ Jenis rumput } & \multicolumn{2}{c}{ Kerapatan relatif (\%) } \\
\cline { 3 - 4 } & Melothria affinis & Integrasi & Non integrasi \\
\hline 1 & Paspalum conjugatum & 1,60 & 1,07 \\
2 & 33,00 & 46,77 \\
3 & Mikania micrantha & 1,79 & 3,68 \\
4 & Asystasia intrusa & 7,99 & 5,09 \\
5 & Davallia denticullata & 4,25 & 0,17 \\
6 & Cyrtococcum patens & 16,95 & 21,47 \\
7 & Cyrtococcum acrescens & 5,15 & 1,67 \\
8 & Ageratum conyzoides & $6,33^{\mathrm{a}}$ & $2,11^{\mathrm{b}}$ \\
9 & Axonopus compressus & 11,19 & 6,22 \\
10 & Nephrolepis bisserrata & 0,53 & 5,88 \\
\hline
\end{tabular}

Keterangan : Huruf yang berbeda mengikuti angka pada baris yang sama menunjukkan berbeda nyata $(\mathrm{P}<0,05 \%)$. 
kalium (K) dan unsur lainnya telah banyak dilaporkan (Yokoyama, 2008).

\section{Indeks Nilai Penting}

Nilai indek penting tertinggi pada tnaman Paspalum conjugatum baik di area non integrasi maupun integrasi dengan presentase $60,80 \%$ di area integrasi dan $88,11 \%$ di area non integrasi. Yang memiliki indeks nilai penting terendah di area integrasi adalah Nephrolepis biserrata dengan presentase 1,93\%, dan Davallia denticullata untuk area non integrasi dengan presentase $0,17 \%$. Indeks Nilai Penting (INP) lebih lengkap disajikan pada Tabel 4.

Berdasarkan Tabel 4 menunjukkan bahwa Paspalum conjugatum memiliki indeks penting yang paling dominan diantara tanaman yang lainnya, hal ini sesuai dengan pernyataan Prawirodiputra (2011) bahwa Paspalum conjugatum memiliki indeks nilai penting tertinggi dibandingkan dengan tanaman lainnya dimana indeks nilai pentingnya mencapai $83,58 \%$, kemudian diikuti oleh Mikania micrantha $(4,25 \%)$, Davallia denticullata dengan presentase terendah $(0,66 \%)$ pada area integrasi.

Menurut Syarifuddin Hutwan (2011) mengungkapkan bahwa Axonopus compressus lebih dominan dengan presentase $86,35 \%$ pada area integrasi dengan kepadatan ternak Ageratum conyzoides juga dominan dengan presentase indeks nilai penting $42,75 \%$. Hasil tersebut berbeda dengan hasil penelitian di perkebunan kelapa sawit PT.Buana Karya Bhakti yang menunjukkan hasil bahwa Paspalaum conjugatum tetap dominan baik dalam area yang terintegrasi maupun non integrasi Tingginya INP
Paspalum conjugatum di area terintegrasi dan non integrasi sapi-sawit PT Buana Karya Bhakti Kalsel karena penyebaranya yang luas dan selalu ada di hampir setiap plot / petak penelitian. Hal ini sesuai dengan pernyataan Tmannetje dan Jones (1992) yang mengemukaan bahwa rumput pahit ini merupakan rumput yang banyak tumbuh di area perkebunan dengan penyebaranya sulit dikendalikan.

Adriadi et al. (2012) mengungkapkan bahwa dibandingkan tanaman yang lain Paspalum conjugatum hampir ditemukan di setiap plot pada lahan perkebunan kelapa sawit sehingga Paspalum conjugatum memiliki indeks nilai penting tertinggi yaitu $54,43 \%$ kemudian diikuti oleh axonopus compressus (7,55\%), Ageratum conyzoides $(4,49 \%)$. Hanya saja, di PT.Buana Karya Bhakti urutanya berbeda, setelah Paspalum conjugatum yang memiliki INP tertinggi untuk area integrasi diikuti oleh Cyrtococcum patens (27,95\%), Axonopus compressus (22,87\%), Asystasia intrusa $(17,82 \%)$, Ageratum conyzoides $(16,13 \%)$, dan Davallia denticulata $(8,48 \%)$. Untuk area yang non integrasi setelah Paspalum conjugatum diikuti oleh Cyrtococcum patens (35,33\%), Mikania micrantha (12,02\%), Asystasia intrusa $(12,43 \%)$, Nephrolepis bisserrata $(12,04 \%)$ dan Axonopus compressus $(11,39 \%)$.

Hasil uji $\mathrm{T}$ atau t-Test dari Tabel 6 menunjukkan bahwa sembilan INP dari sepuluh vegetasi hijauan di area integrasi dan non integrasi tidak berbeda nyata. Hanya rumput Ageratum conyzoides yang berbeda nyata. Hasil di lapangan menunjukkan bahwa Ageratum conyzoides merupakan jenis rumput yang banyak

Tabel 4. Rata-rata indeks nilai penting vegetasi hijauan di area non integrasi dan terintegrasi sapi sawit

\begin{tabular}{llcc}
\hline \multirow{2}{*}{ No } & \multirow{2}{*}{ Jenis rumput } & \multicolumn{2}{c}{ Indeks Nilai Penting (\%) } \\
\cline { 3 - 4 } & & Integrasi & Non integrasi \\
\hline 1 & Melothria affinis & 2,67 & 3,57 \\
2 & Paspalum conjugatum & 60,80 & 88,10 \\
3 & Mikania micrantha & 4,63 & 14,02 \\
4 & Asystasia intrusa & 17,82 & 12,43 \\
5 & Davallia denticullata & 8,48 & 0,17 \\
6 & Cyrtococcum patens & 27,95 & 35,33 \\
7 & Cyrtococcum acrescens & 8,32 & 2,17 \\
8 & Ageratum conyzoides & $16,13^{\mathrm{a}}$ & $3,10^{\mathrm{b}}$ \\
9 & Axonopus compressus & 22,87 & 11,39 \\
10 & Nephrolepis bisserrata & 1,93 & 12,04 \\
\hline
\end{tabular}

Keterangan : Huruf yang mengikuti angka pada baris yang sama menunjukkan berbeda nyata pada taraf uji 5\% $(\mathrm{P}<0,05)$. 
ditemukan hampir di setiap plot penelitian meskipun kemunculannya di setiap plot tidak selalu dalam jumlah yang tinggi.

\section{KESIMPULAN}

Vegetasi tanaman pada area integrasi dan non integrasi sapi sawit memiliki jenis vegetasi yang berbeda berdasarkan kerapatan relatif dan indeks nilai penting tanaman.

\section{DAFTAR PUSTAKA}

Agoes, A. 2010. Tanaman Obat Indonesia. Jakarta. Salemba Medika.

Backer, A. and B. Van Den Brink. 1965. Flora of Java (Spermatophytes Only). I.N.V.P. The Netherland. Noordhof-Groningen.

Bukman.2011.Micaniamicrantha.http://audocume ntsBiosecurity_EnvironmentalPestsIPA_ MicanaVinePP143.ThestateofQuenssland .DepartementofEmployoentEconomicDe velopment.and.Innovate. 25 Juli 2012.

Cronguist, A. 1981. An Integrated System of Clasification of flowering plants. Columba Universaty Press. New York.

Dalimartha, S. 2004. Atlas Tumbuhan Obat Indonesia. Jilid I. Trubus Agriwidya. Jakarta

Damaru. 2011. Alang-alang. Makalah Ekologi Tumbuhan. Universitas Sumatera Utara. Medan.

Depperin. 2007. Gambaran Sekilan Industri Minyak Kelapa Sawit.http://www.kemenperin.go.id/dow nload/289/Paket-Informasi-KomoditiMinyak-Kelapa-sawit

Dinas Peternakan Kalimantan Selatan. 2005. Kebijakan Pembangunan Peternakan Kalimantan Selatan. Makalah Disampaikan dalam Acara Temu Informasi Teknologi Pertanian BPTP Kalimantan Selatan. Banjarbaru, 26-28 Juli 2005

DitJenbun. 2013. Statistik Perkebunan Indonesia Tahun 2008-2012.
Djajanegara, A., M. S. Rangkuti, S. K. Soedarsono. 1998. Pakan Ternak dan Faktor-faktornya. Pertemuan Ilmiah Ruminansia. Departemen Pertanian Bogor.

Farizaldi. 2014. Pengaruh Pemberian Pupuk Kandang dan Abu Sabut Kelapa Terhadap Pertumbuhan Sentro (Centrosema pubescens) Pada Ultisols. Jurnal Seri Sains 16 (1): 71-76.

Fredikurniawan. $2017 . \quad$ Jenis-Jenis Rumput.http://fredikurniawan.com/jenisjenis-rumput-graminae/

Gaspersz, V. 1994.Sistem Informasi Manajemen.Bandung: Armico

Gersinia, L., I. Puspa dan S. P. Kencana. 2015. Tanaman Hias Lengkap Edisi Revisi. Jakarta. Penebar Swadaya.

Haryatun. 2008. Karakteristik Asystasia Intrusa.http://biotrop.org/database.php.

Humphreys, L. R. 1994. Tropical Forages:Their Role in Sustainable Agriculture. Longman Scientific and Technical.

Jayadi, S. 1991.Tanaman Makanan Ternak Tropica.Fakultas Peternakan.Institut Pertanian Bogor.

Kastono, D. 2005. Tanggapan Pertumbuhan dan Hasil Kedelai Hitam terhadap Penggunaan Pupuk Organik dan Biopestisida Gulma Siam (Chromolaena odorata). Ilmu Pertanian. 12 (2): 103116.

Lee, S. A. 1984. Control of Asystasia intrusa in Pineaple with Emphasis on New Techniques. Seminar and Discussion on the Weed Asystasia.West Johore Agric. Dev. Projet. Pontiana

Prawirodiputra, R. M. King dan Robinson. 2007. Ki Rinyuh (Chromolaena L) Gulma Padang Rumput yang Merugikan. Makalah Balai Penelitian Ternak Bogor 16002 
Purwantari, D. N. Nurhayati, B. Tiesnamurti dan Y. Adinata. 2011. Ketersediaan Sumber Hijauan di bawah Perkebunan Kelapa Sawit untuk Penggembalaan Sapi. Wartazoo 25 (1): 047-054.

Rahutomo, S. dan E. S. Sutarta. 2001. Kendala Budidaya Kelapa Sawit pada Tanah Sulfat Masam.Warta PPKS. 9 (1) : 9-15.

Rajaratnam, J. A., K. W. Chan, and T. H. Ong. 1997. Asystasia in Oil Palm Plantations. In: Earp, D. A and W. Newal (Eds). International Development in Oil Palm. Kuala Lumpur: The Incorporated Society of Planters.

Rohaeni, E. S. dan A. Hamdan. 2004. Profil dan prospek pengembangan usahatani Sapi potong di Kalimantan Selatan. Prosiding Lokakarya Nasional Sapi Potong.Yogyakarta, 8-9 Oktober 2004. Pp: 132-139.

Rostini, T. 2014. Produktivitas dan Pemanfaatan Tumbuhan Rawa di Kalsel sebagai
Hijauan Pakan Berkelanjutan. Desertasi. Pascasarjana. IPB. Bogor.

Sampul Pertanian. 2016. Mengenal Gulma Rumput Belulang (Eleusine indica L). http://www.sampulpertanian.com/2016/1 2/mengenal-gulma-rumput-belulangeleusine.html

Sanjaya, B. 2014. Identifikasi dan Pengendalian Gulma pada Lahan Tanaman Kelapa Sawit Menghasilkan (Elaeis guineensis Jacq) di PT. Budidaya Agromakmur.

Siregar, M. E. dan A. Djajanegara.1971. Penggunaan Rumput Brachiaria brizantha dalam Usaha Transformasi Padang Alang-Alang Menjadi Pasture. Buletin Lembaga Penelitian Peternakan No 3: 1-7.

Schultze-Kraft and J. K.Teitzel. 1992. Forages (Isdi) Plant Resources of South East Asia (Prosea). No.4. Wageningen, Netherland and Bogor. Indonesia.

Steenis, C. G. G. J. V. 2003. Flora. PT Pradnya Pramitha, Jakarta. 